\title{
Impact of Gender Segregation on Workplace Advancement of Women in Ghanaian Universities
}

\author{
Akua Ahyia Adu-Oppong1, Stephen Bugu Kendie² \\ ${ }^{1}$ College of Technology Education, University of Education, Winneba, Kumasi \\ ${ }^{2}$ Institute for Development Studies, University of Cape Coast, Cape Coast, Ghana \\ Email: aaaoppong@uew.edu.gh, stephenkendie@gmail.com, skendie@ucc.edu.gh
}

How to cite this paper: Adu-Oppong, A.A. and Kendie, S.B. (2018) Impact of Gender Segregation on Workplace Advancement of Women in Ghanaian Universities. Open Journal of Social Sciences, 6, 301-317.

https://doi.org/10.4236/jss.2018.611023

Received: September 28, 2018

Accepted: November 25, 2018

Published: November 28, 2018

Copyright $\odot 2018$ by authors and Scientific Research Publishing Inc. This work is licensed under the Creative Commons Attribution International License (CC BY 4.0).

http://creativecommons.org/licenses/by/4.0/

\begin{abstract}
This paper is underlined by attempts to understand the extent to which women in Ghanaian universities experience segregation at the workplace. The purpose of this study is to assess the impact of workplace gender segregation processes on the career advancement of women in Ghanaian universities. Data for the study was collected using questionnaires and analysed using both descriptive statistics and correlation analysis. The results of the study showed that women in Ghana experience and encounter segregation as a barrier to advancement in the workplace.
\end{abstract}

\section{Keywords}

Advancement, Gender, Segregation, Workplace

\section{Introduction}

Nearly 50 percent of women around the world are in the labour force, and women constitute approximately one-third of all workers. In spite of this, women remain clustered in lower paid occupations. Segregation of the labour market from a gender perspective has been frequently presented as one of the prevailing characteristics of the global labour market. It is a result of a multidimensional process that manifests itself in differences in gender patterns of representation within occupations (both classified by industries and by professional status) and within different employment status and employment contract groups. Gender segregation means that women and men to a certain extent work in different occupations or in different sectors or under different contractual terms and conditions [1]. 
When women are in the labour force, they usually perform different tasks and work in different sectors than men. The conditions of their employment are on average inferior to those faced by men and are often "atypical" (i.e., part-time, temporary, or casual work, work in the home and in subcontracting). In terms of occupations, for example, nearly two-thirds of women in manufacturing are categorized as labourers, operators and production workers while only a few can be found in the administrative and managerial positions predominantly held by men [2].

While enormous improvements have been made to the workplace and in social systems to advance women's participation and engagement in the workplace, many inequalities remain, such as industrial and occupation gender segregation. Gender segregation is shaped by a multitude of factors that are complex and interconnected, and understanding their complexity is critical to designing interventions to address them. The threatening nature of occupational segregation to workplace advancement makes it necessary to identify and study the variables that impact negatively on the women's advancement.

This study therefore, examined the sources and impacts of workplace segregating processes experienced by women in Ghanaian universities. It also explored the relationship between segregation and workplace advancement of women by attempting to answer two research questions as follows: To what extent do women in Ghanaian universities experience segregation in the workplace? To what extent is the experience of segregation of women of Ghanaian universities impact on their workplace advancement?

\section{Conceptual Issues}

Gender segregation means that women and men to a certain extent work in different occupations or indifferent sectors or under different contractual terms and conditions. Nonetheless, it is essential to question the concept of segregation not only in time and place but also in interactions with the scale of women's employment and career outcomes. Academic debates on gender segregation presents two dimensions of segregation with different specific processes: vertical and horizontal dimensions of segregation. Vertical segregation explains the processes limiting promotion and career opportunities; horizontal segregation identifies situations in which certain economic sectors, professions, or organisational departments are dominated by people of one sex.

When women are in the labour force, they usually perform different tasks and work in different sectors than men. The conditions of their employment are on average inferior to those faced by men and are often "atypical" (i.e., part-time, temporary, or casual work, work in the home and subcontracting) [2]. In terms of occupations, for example, nearly two-thirds of women in manufacturing are categorized as labourers, operators and production workers while only a few can be found in the administrative and managerial positions predominantly held by men. Women workers are usually employed in a limited number of industrial sectors: more than two-thirds of the global labour force in garment production is 
female-accounting for almost one-fifth of the total female labour force in manufacturing [2]. With respect to employment status, the majority of family workers are female and often unpaid. Even when it attracts pay, women's work is valued less than men's. Typically women's earnings average around two-thirds of men's. Overall, no more than one-fifth of the world's wages accrue to women partly because women are usually engaged in low-paying jobs. Even in these jobs, women are usually paid less than men doing comparable work [2].

These patterns suggest that women and men in the labour market are employed in different sectors and that, even when they are in the same sector, they carry out different tasks at different levels of responsibilities [2]. This phenomenon, gender segregation in the labour force, makes female and male workers work in "compartmentalized" activities that usually lead to different rewards and different career opportunities even though workers may have comparable labour market attributes. From the time women and men first went out to work, they have done different jobs [3]. Few occupations employ the sexes in proportion to their representation in the labour force, and workers seldom work with persons of the other sex in the same establishment, much less in the same location and on the same shift [4]. Segregation has been documented at every level of economic organisation: across economic sectors, industries, firms, type of employers (e.g. private, public, self-employed), occupations, jobs, job families, and job ladders as well as across branches, shifts, and ranks [4] [5].

For several decades, occupational gender segregation has been at the heart of debates about gender inequality. From a labour and employment point of view, gender becomes an actual and existing reality, because it is in the workplace where the gender dynamics or gender struggle comes into play. In the workplace, gender is seen as a social indicator of progress and development deserving of policy attention. High levels of segregation have been considered to be a significant factor in the discrepancy between employment outcomes of women and men [6].

\subsection{Gendering Processes in Organisations}

Most feminist writings about organisations have historically assumed that organisational structure is gender neutral [7]. Even though organisational logic appears to be gender neutral with gender neutral theories of bureaucracy, [7] took the position that "underlying both academic theories and practical guides for managers is a gendered substructure that is reproduced daily in practical work activities and, somewhat less frequently, in the writings of organisational theorists" [8]. [9] pointed out that it is rather that assumptions about gender lie behind the documents and contracts used to structure organisations which also give the commonsense ground for theorising about them. [10] expressed the opinion that in our society, organisations have been central to creating and maintaining our perception of what is suitable for women and men. While the participation of women in the workforce has changed dramatically over the last few decades, organisations have not followed the same path. The changes with 
new jobs and work patterns have, according to scholars, not succeeded in neutralising occupational segregation at the organisational level, and as [11] maintained "we know now that gender segregation is an amazingly persistent pattern and that the gender identity of jobs and occupations is repeatedly reproduced, often in new forms". Acker built on the work of [12] to support her argument that gender differences in organisational behaviour are due to structure rather than to characteristics of women and men as individuals.

Acker considered that there is a sex structuring in organisations, which consists of differentiation of women's and men's jobs, a hierarchical ordering of those jobs so that men are higher than women and are therefore not expected to take orders from women leading to men having more power than women [13]. [14] claimed that even where women have entered occupations traditionally dominated by men, as has happened recently to a certain extent in a lot of countries, women are likely to be found in lower status and lower paid positions than men. Researchers have taken the viewpoint that women are subject to gendered organisational structures and regimes within organisations, where women's careers and their experiences of the workplace are defined by male work patterns [15] [16] [17] [18]. Reskin argued that research done by scholars such as Bielby in 1996 [19], and Britton in 2001 [20] and several others has revealed that levels of inequality in work organisations are affected by organisational demography, organisational leadership, the degree to which personnel practices are formalised, recruitment methods, external pressure, as well as the availability of slack resources [21].

Acker's formal statement of a "theory of gendered organisations" systematized more than a decade of insights by researchers in the area of organisations [22]. According to her, there are a number of ways of seeing organisations and occupations as gendered; first, and most basically, one can argue that the ideal-typical bureaucratic organisation is inherently gendered. Acker argues that to say that an organisation is gendered is to say "that advantage and disadvantage, exploitation and control, action and emotion, meaning and identity are patterned through and in terms of a distinction between male and female, masculine and feminine." To say that organisations are inherently gendered implies that they have been defined, conceptualized, and structured in terms of a distinction between masculinity and femininity, and presume and will thus inevitably reproduce gendered differences. Ultimately, to the extent that gendered characteristics are differentially valued and evaluated, inequalities in status and material circumstances will be the result.

Acker distinguishes four dimensions of the process by which gender differences and hierarchies are constantly produced and reproduced. These are the gendered division of labour, gendered interaction, gendered symbols and gendered interpretations of one's position in the organisation. This process could occur at any organisational level outlined by Acker (structure, ideology, policy and practice, interaction, and identity, and gender could be deployed by organisations, by workers themselves, or both). The author is of the view that gender 
can be invoked by organisations through such mechanisms as collegial, informal recruiting practices or the promulgation of policies that place a premium on gendered characteristics, such as physical strength or freedom from domestic responsibilities. Gender may also be mobilized as a resource by workers, for example, to maintain positions of privilege or reinforce threatened identities [23]. In any case, if one can identify those factors that are conducive to less gender segregation and inequality in organisational or occupational or labour force environments, then the possibility of replicating those conditions becomes much more realistic.

In Acker's theory different gender hierarchies are first produced through an unofficial gendered division of labour. For example, in a university organisation, the women's role might be to act as 'mothers of the department': by creating a comfortable atmosphere, making coffee and organizing different social events. These tasks are little valued in the workplace and attract little credit in terms of career development. The gender pay gap also reflects this unofficial division of labour and the values attached to it [24].

Secondly, theories of gendered organisation highlight the ways in which interaction and communication is gendered. A number of studies have drawn attention to the ways in which universities function on the basis of tacit knowledge [25] [26]. In such organisational cultures, men's insider networks for interaction and for transmitting information are emphasized. Part of gendered interaction entails gendered evaluations of success, in which case the work of women and men might be evaluated in different ways [27].

Thirdly, gendered symbols, images and forms of consciousness also are part of the way a gendered organisation works. Different male heroes, gentlemen's clubs and men's networks are examples of these. Language can produce gendered images and academic titles, such as "masters" and "fellows", carry a masculine sign [28]. Finally, women's and men's ways of interpreting their positions and chances are part of the way a gendered organisation works [29].

\subsection{Consequences and Effects of Occupational Gender Segregation}

Occupational segregation based on gender is one of the main factors contributing to women's inequality in the labour market [30]. Occupational gender segregation is to a large extent a women's issue, since it is more detrimental for them than for men. To begin with, women are employed in a narrower range of occupations than men [31]. According to Anker, male-dominated non-agricultural occupations are on average seven times as numerous as female-dominated occupations. Furthermore, Female occupations are generally less attractive, with their tendency toward lower pay, lower status and fewer advancement possibilities. One frequently mentioned example of the restricted career path of women is the famous "glass ceiling" preventing women from occupying the higher levels

of management, demonstrated by the fact that almost $90 \%$ of managers, high level administrators and legislative officials in the world are men [32]. 
The effects and consequences can be many; [33] stated that it is "the primary mechanism in capitalist society that maintains the superiority of men over women, because it enforces lower wages for women in the labour market". Gender Occupational Segregation is an important source of market inefficiency and rigidity [34]. It represents exclusion, discrimination and wasteful use of human resources. Since many of the best qualified and most appropriate persons for an occupation may effectively be excluded because of their gender. Anker argued that occupational gender segregation is disadvantageous to women, and as a result, it has a fundamental negative effect on how men view women and on how women view themselves.

Alvesson and Billing illustrated a crucial factor arguing that 'the concept of segregation implies that the division of labour is not based on "natural" skills or on the "free will" of individuals but that it needs explanation, especially because the segregation also results in inequalities, mainly that women are concentrated within low pay areas, whereas men's jobs are better paid and offer better promotion prospects' [35]. Occupational gender segregation has been at the heart of debates as a serious form of gender inequality [36]. This gender inequality has been considered to be a significant factor in the discrepancy between the wages of women and men and has been seen to be strongly related to inequalities in pay, career prospects and employment protection between men and women. The inequalities of segregation are primarily located in market employment, but they spillover into all aspects of life. Thus, the subject raises significant questions of social justice, of the efficient utilization of human resources, of structuring of the labour markets, and of wider social aspects of work and the family life [37].

Further, the resilience of occupational segregation is seen as having essential implications for women and men, economic growth and efficiency and labour market rigidities [38]. In addition, the persistence of expectations and gender stereotypes of what is appropriate for women and men to do has negative effects on education and training and can therefore result in gender-based inequalities which might also be carried on into future generations. Melkas and Anker claimed that a stringent division of work between women and men limits labour market options. It can therefore lead to the devaluation of work and thereby cause gendered pay differentials. This cannot be explained by differences in terms of educational levels or work experience. In fact, they argued that as a consequence occupational gender segregation leads to a lack of equal opportunities, which is one of the cornerstones of overall equality in society [39].

Blackburn et al. argued that occupational gender segregation has generally been understood as a structure of gender inequality, and segregation indices have been used as direct measures of this inequality [36]. Nevertheless, they recognise that there are some awkward findings, such as the high segregation level in egalitarian Sweden, which is believed to be quite equal. Blackburn et al. argued that the reason why some countries are ranked high on both equality and segregation might be that studies are pointing to overall segregation which combines both horizontal and vertical axes. Therefore, when analysing occupational 
segregation, the need to distinguish between the two different forms of occupational segregation is central [28] [40]. It is the vertical axis of segregation that is often the focus of public policy and debates about women's equality. The idea of a glass ceiling is a common metaphor for vertical gender segregation and lack of equality [41]. In addition, it is also argued that some occupations that do not appear to be segregated can, nonetheless, be internally segregated. For this study, the focus is centrally concerned with vertical gender segregation and equality as the focus of enquiry.

\section{Methodology}

The study adopted a survey research design. Data on occupational gender segregation studies and women's advancement issues were gathered by means of carefully designed questionnaires.

\subsection{Study Participants}

The study sample was drawn from women occupying middle level career and managerial positions in both private and public universities in Ghana. A total of one hundred and fifty (150) women participants were drawn for the study. The functions of these women in their universities cut across teaching and nonteaching administrative professions. They included women employees within the academic and administrative hierarchical levels. This allowed for comparisons between the hierarchical levels. The participants of this study were women who were senior academic and administrative/professional staff with the rank of senior lecturer and analogous positions and above and had worked in the university for a period of more than five years. This was to ensure validity of information received as issues of tenure and promotions are attained over specific time periods. They include women with administrative positions within the teaching and non-teaching administrative hierarchies; who are referred to as academic administrators and administrative professionals respectively in the study.

\subsection{Data Collection}

The study gathered data using questionnaires. The questionnaire was divided into four parts. The first part consisted of demographic variables. The second part consisted of questions based on themes inAcker's theory of gendered organisations in assessing institutional practices and the third and four part contained variables that measured responses of participants based on the perceptions on gender inequality in the workplace.

In the first part, data on the following demographic variables of the study participants was collected; 1) age, 2) institution type, 3) highest educational level attained, 4) tenure in administrative position. In the second part, data from the themes in Acker's theory of gendered organisations was collected. The response option in this section was based on a five point Likert scale in which participants 
were required to respond to statements on the scale provided by ticking the responses that most closely fit their opinion. In the third part, data from specific components of Acker's Inequality regimes were collected. The response option in this section was also based on a five point Likert scale.

There is significant supportive data for the reliability of the scales employed in this study, for example, [42] has proposed that the minimum acceptable reliability coefficients levels of the variables should be (0.80 to 0.96).The study reports reliability coefficients in the measure of occupational gender segregation as; gendered division of labour $(\alpha=0.87)$, gendered interaction $(\alpha=0.86)$, gendered interpretations ( $\alpha=0.89)$, gendered symbols $(\alpha=0.85)$, and gendered conceptualisation of social structures in the organization $(\alpha=0.80)$.

In the measure of the varying characteristics of inequality regimes as barriers to advancement, the following reliability results were realised: bases of inequality ( $\alpha=0.87$ ), shape and degree of inequality $(\alpha=0.80$ ), organizing processes that create and recreate inequalities $(\alpha=0.78)$, and invisibility of inequalities $(\alpha=0.68)$. During data collection, permission was first sought from the university authorities concerned to engage participants in their institutions in the study. After approval had been given, the questionnaires were purposively administered to a sample of 150 women in the identified positions in their respective universities. Each participant was given a time period of two weeks to answer and return the questionnaire. A total of one hundred and forty two (142) questionnaires, out of the one hundred and fifty (150) distributed, were returned, representing a response rate of ninety five percent (95\%). All the returned questionnaires from the participants were usable with all parts fully scored.

\section{Analysis and Results of the Study}

\subsection{Appraisal of Study Participants' Demographic Data}

Analysis is done based on data collected through the use of questionnaires and analyzed by means of both descriptive statistics and correlation analysis using SPSS version 2.0. The demographic characteristics of the participants are summarized in Table 1. In terms of age, 83 (58\%) of the participants were 45 years old and above, while 59 (42\%) participants were 44 years or below. Regarding the type of institution, 78 (55\%) participants were from public universities, 64 (45\%) participants were from private universities. All participants had postgraduate degrees with $36(25 \%)$ having additional doctoral degrees. A total of 39 (27\%) of the participants had attained tenure whilst the remaining 103 (73\%) were yet to attain tenured ranks.

\subsection{Appraisal of Impact of Gender Segregation on Workplace Advancement}

The results from the correlation analysis of participants' scores on the relationship between organisational variables and career advancement are summarised in Table 2. 
Table 1. Results of respondents' demographic characteristics.

\begin{tabular}{|c|c|c|c|}
\hline Demographic Variables & Categories & Number & Percentage (\%) \\
\hline \multicolumn{4}{|l|}{ Age } \\
\hline & 24 to 44 years & 59 & 42 \\
\hline & 45 years and above & 83 & 58 \\
\hline \multicolumn{4}{|l|}{ Type of institution } \\
\hline & Public & 78 & 55 \\
\hline & Private & 64 & 45 \\
\hline \multicolumn{4}{|c|}{ Highest educational level attained } \\
\hline & Post graduate & 142 & 100 \\
\hline \multicolumn{4}{|c|}{ Tenure in administrative position } \\
\hline & Tenure & 39 & 27 \\
\hline & Non Tenure & 103 & 73 \\
\hline \multicolumn{4}{|l|}{ Occupational group } \\
\hline & Academic Administrators & 67 & 47 \\
\hline & Administrative Professionals & 75 & 53 \\
\hline \multicolumn{4}{|l|}{ Position } \\
\hline & Dean/Director & 41 & 29 \\
\hline & Head of Department & 101 & 71 \\
\hline
\end{tabular}

Notes: The figures indicate the share of women who occupy administrative positions in teaching and non-teaching occupational group in the sampled universities. Women in the two occupational groups are classified into: 1 Academic administrators (teaching-including women with faculty positions); 2 Administrative Professionals (non-teaching-including women with positions in administration such as finance, audit, development, registry etc). Source: Authors' classification based on data of sampled participants.

Table 2. Correlation coefficients for relationship between organisational factors and career advancement.

\begin{tabular}{cc}
\hline Organisational Factors & $\begin{array}{c}\text { Correlation Coefficients for Relationship between } \\
\text { Organisational Factors and career advancement }(\alpha)\end{array}$ \\
\hline $\begin{array}{c}\text { Gender conceptualisation of social } \\
\text { structures in the organisation } \\
\text { Gender division of labour }\end{array}$ & $0.59^{* *}$ \\
Gender interaction & $0.58^{* *}$ \\
Gender symbols & $0.52^{* *}$ \\
Gender interpretations & $0.17^{*}$ \\
\hline
\end{tabular}

${ }^{*}$ correlation is significant at the 0.05 level (2-tailed); ${ }^{* *}$ correlation is significant at the 0.01 level (2-tailed). Source: same as in Table 1.

The results indicate that the participants consider each organisational variable as a barrier to advancement. The scores were: Gender conceptualisation of social structures in the organization ( $\alpha=0.59, p \leq 0.01)$; gender division of labour ( $\alpha=$ $0.58, p \leq 0.01)$; gender interaction $(\alpha=0.52, p \leq 0.01)$; gender symbols $(\alpha=0.17$, $p \leq 0.01)$ and gender interpretations $(\alpha=0.19, p \leq 0.01)$.Even though the par- 
ticipants' consider each organisational variable as a barrier to advancement, Gender conceptualisation of social structures in the organisation, gender division of labour and gender interaction had higher scores in contributing highly as a source of barrier of advancement. Thus a statistically significant positive relationship exist between gender conceptualisation of social structures in the organisationand advancement ( $\alpha=0.59, p \leq 0.01)$, as well as gender division of labourand advancement $(\alpha=0.58, p \leq 0.01)$ and gender interaction and advancement $(\alpha=0.52, p \leq 0.01)$. This indicates that gender conceptualisation of social structures in the organisation, gender division of labour and gender interaction have stronger positive relationship with with limited career advancement opportunities for women.

However, a statistically significant, but weak positive relationship exist between gender symbols and advancement $(\alpha=0.17, p \leq 0.05)$ and gender interpretations and advancement $(\alpha=0.19, p \leq 0.01)$.

\subsection{Analysis of the Occupational Based Impact of Segregation on Career Advancement Induced by Organisational Factors}

Respondents' mean (m) scores; standard deviations (sd) and z-values for the organisational factors inducing limited career advancement opportunities are shown in Table 3.

In this section, the five components of Acker's gendered organisational theory-gender conceptualisation of social structures in the organisation, gender division of labour, gender interaction, gender symbols and gender interpretations were tested to examine the extent to which segregation impacts on the career advancement of academic administrative and administrative professional women in Ghanaian universities.

The results show that the academic administrators reported higher scores ( $\mathrm{m}$ $=22.50, \mathrm{sd}=3.73$ ) for limited advancement opportunities induced by gender division of labour than their administrative professional colleagues $(\mathrm{m}=17.93$,

Table 3. Respondents' mean scores, standard deviations, and z-score estimates for segregation induced by organisational factors.

\begin{tabular}{|c|c|c|c|c|c|c|}
\hline \multirow[t]{2}{*}{ Organisational Factors } & \multicolumn{2}{|c|}{$\begin{array}{c}\text { Academic } \\
\text { Administrators' } \\
\text { Mean Scores }\end{array}$} & \multicolumn{2}{|c|}{$\begin{array}{l}\text { Administrative } \\
\text { Professionals' } \\
\text { Mean Scores }\end{array}$} & \multirow[t]{2}{*}{$\begin{array}{c}Z \\
\text { Scores }\end{array}$} & \multirow{2}{*}{$\begin{array}{l}\text { Critical } \\
\text { Z } \\
\text { value }\end{array}$} \\
\hline & $\mathrm{m}$ & sd & $\mathrm{m}$ & sd & & \\
\hline $\begin{array}{l}\text { Gender conceptualisation of social } \\
\text { structures in the organisation }\end{array}$ & 18.1 & 3.87 & 14.82 & 3.31 & $4.97^{\star *}$ & \multirow{5}{*}{1.645} \\
\hline Gender division of labour & 22.55 & 3.73 & 17.93 & 3.67 & $6.79^{\star *}$ & \\
\hline Gender interaction & 12.53 & 1.24 & 12.9 & 1.49 & 1.48 & \\
\hline Gender symbols & 17.68 & 3.11 & 18.82 & 4.65 & $5.77^{\star *}$ & \\
\hline Gender interpretations & 11.3 & 2.35 & 11.48 & 1.63 & 0.49 & \\
\hline
\end{tabular}

${ }^{*}$ correlation is significant at the 0.05 level (2-tailed); ${ }^{*}$ correlation is significant at the 0.01 level (2-tailed). Source: same as in Table 1. 
$s d=3.67)$. This is indicative of the fact that Ghanaian female academic administrators experience higher levels of limited advancement opportunities in relation to gender division of labour in comparison to their administrative professional $(\mathrm{z}=6.79, p \leq 0.01)$.

Regarding gender symbols, the administrative professionals were found to experience significantly more limited advancement opportunities $(\mathrm{m}=18.82$, sd $=4.65)$ than the academic administrators $(\mathrm{m}=17.68, \mathrm{sd}=3.11)$. This shows that the administrative professionals experience more limited advancement opportunities as a result of gender symbolisation in the workplace than their academic administrators colleagues $(\mathrm{z}=5.77, p \leq 0.01)$.

The academic administrators reported higher limited advancement opportunities due to gender conceptualisation of social structures in the organisation ( $\mathrm{m}$ $=18.10, \mathrm{sd}=3.87)$ compared with the administrative professionals $(\mathrm{m}=14.82$, $\mathrm{sd}=3.31)$. This shows that the academic administrators reported being more negatively affected by the perception of individuals in the organisation which seems to support men as ideal for top administrative positions than their administrative professional colleagues $(z=4.97, p \leq 0.01)$. The difference in the level of limited advancement opportunities induced by gender interpretations on the administrative professionals and academic administrators is statistically insignificant $(\mathrm{z}=0.49, p \geq 0.05)$, even though the mean score for the academic administrators $(\mathrm{m}=11.48, \mathrm{sd}=1.63)$ was higher than that of the administrative professionals $(\mathrm{m}=11.30 \mathrm{sd}=2.35)$. Therefore, both the academic administrators and administrative professionals appeared to be equally affected by gender interpretations as inhibiting advancement opportunities for women in Ghanaian universities.

The difference in the level of limited advancement opportunities induced by gender interactions in the workplace on the administrative professionals and academic administrators is statistically insignificant $(\mathrm{z}=1.48, p \geq 0.05)$, even though the mean score for the academic administrators $(\mathrm{m}=12.90$, $\mathrm{sd}=1.49)$ is higher than that of the administrative professionals $(\mathrm{m}=12.53$; $\mathrm{sd}=1.24)$. As a result, both the academic administrators and administrative professionals appeared to be equally affected by limited advancement opportunities that emanate from gender interactions in the workplace.

\subsection{Discussion of Results of the Study}

This study examined the relationship between gender segregation and workplace advancement of women in Ghanaian universities. It assessed the extent to which the themes of Acker's gendered organisational theories-gender conceptualisation of social structures in the organisation, gender division of labour, gender interaction, gender symbols and gender interpretations, related to limited advancement opportunities of women administrators in Ghanaian universities. The results show that all the organisational factors measured have positive relationships with limited advancement opportunities for women. The implication drawn from the analysis shows that academic administrators in Ghanaian uni- 
versities experiences more limited advancement opportunities resulting from gender division of labour and gender conceptualisation of social structures in the organisation than administrative professional women; but not from gender symbols, which tend to affect the administrative professionals much more. Even though the academic administrators and administrative professionals, statistically appeared to encounter the same levels of limited advancement opportunities induced by gender interpretations, and also limited advancement opportunities due to gender interactions, the differences in their mean scores have realistic social value in the Ghanaian socio-cultural context. Cultural norms seem to be mirrored in the social structures of the Ghanaian workplace. By implication, it can be said that academic administrators are more affected than their administrative professional colleagues by the limited advancement opportunities resulting from these two organisational factors, irrespective of the smallness of differences in their mean scores. These findings indicate that the participants view each organisational variable as sources of limited advancement opportunities.

Building on other research findings such as [25], [27] and [29], this study has provided further evidence that inhibitors of advancement opportunities such as gender interpretations and gender division of labour are significantly related to limited advancement opportunities among women administrators. The implication of this finding is that when women, irrespective of their occupational-hierarchy, find themselves in top administrative positions in Ghanaian universities, there is the tendency for them to experience limited advancement opportunities due to gendered organisational processes. Many studies have pointed out specific limited advancement opportunities factors for women in higher education management. These include factors inherent in the workplace setting, role-based limited advancement opportunities, relationships, career development factors, organisational structure and climate [27]. In this study, these five gendered organisational themes are identified as key sources of job limited advancement opportunities to women. This finding is also consistent with those of [24] and [27]. Consistent with the findings of this study is the observation by [23] [24] and [34] that individuals who constantly have to struggle to move up the organisational ladder within the organisational hierarchy will always perceive gender symbols as an inhibitor to career advancement. Such women are also likely to perceive inadequate feedback about performance, under-promotion, and denied promotions as limitations to advancement.

The study results also showed positive relationship between gender conceptualisation of social structures in the organisation and limited advancement opportunities. Thus the participants reported gender conceptualisation of social structures in the organisation as a limitation to advancement opportunities. The administrative role creates a sense of independence in role performance, and one's own ability to stand alone in decision making. Therefore this situation might have created the perception that administrative roles are the preserve of men who are socially perceived to have such attributes, therefore creating a barrier for women to advance to such positions. This finding is also consistent with 
those of [14] and [24].

The study further examined limited advancement opportunities and its relationship with two occupational hierarchies. The findings indicate that the academic administrators reported significant levels of limited advancement opportunities in relation to gender division of labour in comparison to their administrative professional counterparts. The differences observed in their reports are significant, indicating that the academic administrators experience more limited advancement opportunities relating to gender division of labour in comparison to their administrative professional counterparts. The academic administrators are more exposed to limited advancement opportunities that emanate from gender division of labour and gender conceptualisation of social structures in the organisation. This finding tends to support those found by [29] which indicates that academic administrators experience high conflict between the two roles they occupy (teaching/research-administrative roles),implying that women academic administrators in Ghana tend to experience ambiguities in their administrative responsibilities due to conflict between their teaching/research and administrative work roles.

Similarly, [27] found that academic women scored significantly higher on sources of limited advancement opportunities from factors intrinsic to the job, managerial role, career achievement, organisational structure and climate and relation with others. In relation to gender symbols, our findings further indicate that the administrative professionals report this organisational variable as a significant source of limited advancement opportunities in relation to the academic administrators. This implies that when administrative professionals perceive that their chances of advancing within their careers are symbolized by gender, they are more likely to experience limitations to advancement opportunities.

\section{Conclusions}

Gendering processes in the workplace can be very subtle but its impact on workplace advancement of women can be daring. But many organisations fail to see any relationship between gender segregation and limited advancement opportunities for women and therefore little or no attention has been given to it. The findings of this study have shown that women are more likely to perceive organisational processes as a limitation to advancement opportunities in the workplace. Though many studies have indicated negative relationship between workplace gender segregation and advancement opportunities for women, this study has shown that segregating factors work differently in women engaged in different occupations in higher education. This study therefore, concluded that, despite the enormous limitations to advancement opportunities experienced by women in university administration in Ghana, there are differences in the way these segregation inducing organisational factors impact on women across occupations in Ghanaian universities.

The findings from this study suggest the following implications. Universities need to focus attention to the organisational factors that are likely to act as a li- 
mitation to advancement opportunities for women in the workplace. In order to minimize the impact of workplace gender segregation on women's career advancement, universities should clearly outline and communicate its progression expectations devoid of gender symbolisations, give enough opportunity for women to develop their career and move to higher positions in the universities, and embark on a structure that will enhance effective, productive and equal participation of the sexes.

The study has shown that academic administrators and their administrative professional counterparts are likely to report some differences experiences in their perception on sources of limited advancement opportunities. For this reason, this study propose that particular attention be paid to occupational and hierarchical differences in the impact of segregation on women's advancement in the workplace as the themes in the gendered occupational theories impact differently on women in different occupations. This is because the study showed that the hierarchical levels within the two occupational groups differed with regard to which work conditions were associated with different dimensions of segregation. Advancement opportunities of academic administrators that were associated with segregation differed somewhat from the administrative professionals. Administrative professionals, particularly middle managers, have more opportunities of advancement as compared to the academic administrators. Administrative professionals work tasks are more strategic and long-term, which makes it easier for them to take advantage of advancement opportunities in the workplace. In contrast, middle management academic administrators have fewer such opportunities, because they have different responsibilities (both in teaching, administration and research) and different requirements for being present at work (board and committee commitments). Therefore they may be unable to take advantage of the advancement opportunities available to them. This occupational and hierarchical difference in the impact of segregation on women's advancement in the workplace requires particular attention. This is important in understanding occupation specific dynamics in gender segregation studies and relevant to universities' attempt to provide support and design policies to tackle the sources of limitation to advancement opportunities for women in the workplace.

\section{Significance of the Study}

This study made contributions in refining and extending previous academic knowledge on workplace gender representation by extending the scope of study to explore individual and institutional level factors in explaining the issues of persistent gendered hierarchies and gendered practices on women's workplace advancement. This study also has important policy implications that would lead to new orientation in formulation and implementation of new workplace policies and strategies. Practically, the results of this study provides evidence to support the need for the institution of laws in order to achieve greater equality 
and result in women having greater visibility in public life and improved overall equality in the workplace.

\section{Conflicts of Interest}

The authors declare no conflicts of interest regarding the publication of this paper.

\section{References}

[1] Emerek, R., Figueiredo, H., González, P., Gonäs, L. and Rubery, J. (2008) Indicators on Gender Segregation. Research Center on Industrial, Labour and Managerial Economics, Porto.

[2] Tzannatos, R. (2008) Occupational Segregation by Sex in Nordic Countries: An Empirical Investigation. International Labour Review, 136, 341-364.

[3] Goldin, C. and Rouse, C. (2000) Orchestrating Impartiality: The Impact of "Blind" Auditions on Female Musicians. The American Economic Review, 90, 715-741.

[4] Bielby, W.A. (2006) Men and Women at Work: Sex Segregation and Statistical Discrimination. American Journal of Sociology, 91, 759-799.

[5] Reskin, B. and Roos, P. (2000) Job Queues and Gender Queues. Temple University Press, Philadelphia.

[6] Forret, M. (2004) Networking Behaviors and Career Outcomes: Differences for Men and Women? Journal of Organizational Behavior, 25, 419-437.

[7] Acker, J. (1990) Hierarchies, Jobs, Bodies: A Theory of Gendered Organizations. Gender and Society, 4, 139-158.

[8] Seierstad, C. and Opsahl, T. (2011) For the Few Not the Many? The Effects of Affirmative Action on Presence, Prominence, and Social Capital of Female Directors in Norway. Scandinavian Journal of Management, 27.

[9] Acker, J. (1994) The Gender Regime of Swedish Banks. Scandinavian Journal of Management, 10, 117-130.

[10] Ely, R.J., Foldy, E. and Scully, M. (2003) Reader in Gender, Work, and Organization. Malden, Mass.; Oxford, Blackwell.

[11] Acker, J. (2004) Gender, Capitalism and Globalization. Critical Sociology, 30.

[12] Kanter, R.M. (1997) Men and Women of the Corporation. Basic Books.

[13] Acker, J. (2009) Gendered Institutional Theory: Sex Roles and Gendered Institutions. American Journal of Sociology, 91, 759-799.

[14] Melkas, H. and Anker, R. (2008) Gender Equality and Occupational Segregation in Nordic Labour Markets. International Labour Office, Geneva.

[15] Crompton, R. and Le Feuvre, N. (2006) Continuity and Change in the Gender Segregation of the Medical Profession in Britain and France. International Journal of Sociology and Social Policy, 23.

[16] Cockburn, C. (1998) The Gendering of Jobs: Workplace Relations and Reproduction of Sex Segregation. In: Cockburn, C., Ed., Gender Segregation at Work, Open University Press, Philadelphia.

[17] Acker, J. (2006) Inequality Regimes: Gender, Class, and Race in Organizations. Gender and Society, 20, 441-464. https://doi.org/10.1177/0891243206289499

[18] Acker, J. (2006) Class Questions: Feminist Answers. Rowman \& Littlefield Publishers, Lanham. 
[19] Bielby, W.A. (1996) Sex Segregation within Occupations. American Journal of Sociology, 91, 759-799. https://doi.org/10.1086/228350

[20] Britton, D. (2000) The Epistemology of the Gendered Organization. Gender \& Society, 14, 418-434. https://doi.org/10.1177/089124300014003004

[21] Reskin, B. (2008) The Realities of Affirmative Action. American Sociological Association, Washington DC.

[22] Acker, J. (1994) In the Way of Women Men's Resistance to Sex Equality in Organizations-Cockburn, C. Signs, 19, 504-506. https://doi.org/10.1086/494896

[23] Acker, J. (1996) Regimes of Inequality: A Theory of Gendered Organisations. Gender and Society, 16, 315-339.

[24] Acker, J. (2009) From Glass Ceiling to Inequality Regimes. Sociologie du Travail, 51, 199-217. https://doi.org/10.1016/j.soctra.2009.03.004

[25] Husu, L. (2011) Sexism, Support and Survival. Academic Women and Hidden Discrimination in Finland. Social Psychological Studies 6. University of Helsinki, Helsinki, 48-53.

[26] Stolte-Heiskanen, V. (2001) Handmaidens of the "Knowledge Class": Women in Science in Finland. In: Plöger, L., Ed., Women in Science: Token Women or Gender Equality, Berg, Oxford, 35-62.

[27] Brouns, B. (2013) The Puzzle of Gender Segregation and Inequality: A Cross-National Analysis. European Sociological Review, 16, 119-135.

[28] Blackburn, R., Browne, J., Brooks, B. and Jarman, J. (2002) Explaining Gender Segregation. The British Journal of Sociology, 53, 513-536. https://doi.org/10.1080/0007131022000021461

[29] Davis, M. (2013) The Advancement of Gender Segregation Regimes. The American Journal of Sociology, 105, 1658-1701.

[30] Anker, R. (1997) Political Economy: Working for Better Times: Rethinking Work for the 21st Century. ILO, Geneva.

[31] Blackwell, L. (2001) Occupational Gender Segregation and Part Time Work in Modern Britain. Gender, Work and Organization, 8, 146-163. https://doi.org/10.1111/1468-0432.00126

[32] ILO (2000) International Labour Report. ILO, Publishing Company, Geneva.

[33] Hartman, S.G. (1976) Feminism and Methodology: Social Science Issues. Indiana University Press, Bloomington, Open University Press, Milton Keynes.

[34] Mohd, A. (2012) Gender Occupational Segregation in Africa: A Study of Eritrea. Barnolipi, 1, 2249-2666.

[35] Alvesson, M. and Billing, Y.D. (2007) Understanding Gender and Organizations. Sage, London.

[36] Blackburn, R.M., Brooks, B. and Jarman, J. (2001) The Vertical Dimension of Occupational Segregation. Work, Employment and Society, 15, 511-538. https://doi.org/10.1177/09500170122119138

[37] Ely, R.J. (2000) Feminist Critiques of Research on Gender in Organizations. Center for Gender in Organizations, Simmons Graduate School of Management, Boston, Working Paper No. 6.

[38] Clark, R., York, A. and Anker, R. (2003) Cross-National Analysis of Women in the Labour Market. In: Women in the Labour Market on Changing Economies, Oxford University Press, Oxford, 13-34.

[39] Reskin, B. (2009) The Determinants and Consequences of Workplace Sex and Race 
Composition. Annual Review of Sociology, 25, 335-361.

https://doi.org/10.1146/annurev.soc.25.1.335

[40] Glover, J. and Kirton, G. (2006) Women, Employment and Organizations. Routledge, London.

[41] Smulders, A.E.M. (2008) Creating Spaces for Women: Gender Linked Factors in Managing Staff in Higher Education Institutions. UNESCO, International Institute for Educational Planning, Paris.

[42] Nunnally, J.L. (2004) Psychometric Theory. McGraw Hill, New York. 